of mitral stenotic disease and its consequences that digitalis is detrimental, and on the clinical features of this phase Sir James Goodhart has cast valuable light by emphasising the points he has done in his interesting paper. What is true of mitral stenotic cases is likewise true of those cases of aortic regurgitation in which digitalis has been found to be prejudicial, and for the same reason-namely, increased aspiration of ventricular diastole in the presence of defect in the aortic cusps. In such cases there is little undue left ventricular repletion.

Sir James Goodhart's article contains other points of practical importance, and I feel sure that I am not alone among your readers in expressing the hope that your columns may contain more "old. fashioned" papers on these subjects of equal interest and value.-I am, Sir, yours faithfully,

Upper Berkeley-street, W., July 10th. ALEXANDER MORISON.

\section{BOILED VACCINES.}

\section{To the Elitor of THE $\mathrm{T}$ ANCET.}

SIR,-Dr. David Sommerville, in his letter under this heading in THE LANCET of July 10th, claims that boiled vaccines are more efficacious in infections with staphylococci and micrococcus catarrhalis than are vaccines prepared by being heated in the usual way to $58^{\circ}-60^{\circ} \mathrm{C}$., and that phagocytosis is distinctly more active as measured by the number of cocci englobed in a certain number of patients treated by him. Obviously the fallacy resulting from auto-inoculation cannot be excluded in these cases. The experimental inoculation of healthy rabbits avoids this fallacy, and I have investigated the effects of sterilising vaccines of staphylococci in various ways (including boiling) and carefully ascertained the opsonic index which resulted from the inoculation of similar doses into rabbits. My results are set forth in detail in a paper about to appear in the Joumal of Hygiene and now in the hands of the editor of that journal. In the case of the boiled vaccine the opsonic index rose to $2 \cdot 49$, whilst in the case of the vaccine heated in the usual way to $60^{\circ} \mathrm{C}$. it rose to 2\%92. Although there is no very great difference in these results, the figures are slightly in favour of the vaccine heated to $60^{\circ} \mathrm{C}$. Dr. Sommerville's claim of the superiority of boiled vaccines cannot, I think, be substantiated.

$$
\text { I am, Sir, yours faithfully, }
$$

Frank E. TaYLOR, M.A., M.D., M.Sc., F.R.C.S. July 12th. Pathologist, Royal Westminster Ophthalmic Hospital.

\section{THE INDEMNITY POLICY OF THE MEDICAL DEFENCE UNION.}

To the Editor of THE LANCET.

Sir,-In the annual report of the London and Counties Medical Protection Society which has just been brought before my notice appears a state. ment to the effect that the indemnity policy which that society has entered into is superior to that of other similar societies in that the costs and damages are paid when an action is lost by the member either as a plaintiff or defendant. This condition of insurance is exactly similar to that which obtains in the Medical Defence Union indemnity policy, as a defensive action covered by the policy entered into by their members with the Yorkshire Insurance Company is interpreted to refer to the member either as plaintiff or defendant. It often happens that a member being libelled or slandered, a duty involves upon the Medical Defence Union to defend his professional repute by raising an action on his behalf, and if the member is insured in the Yorkshire Insurance Company the policy covers costs of the other side should a verdict adverse to him result.

Frequently the best method of defence is the institution of proceedings, and it is well recognised both by the Union and the "Yorkshire" that such proceedings constitute "defensive actions." I ask you to allow me to communicate with the profession through your columns, as being the quickest and best means of correcting any misunderstanding which may have arisen from the misleading statement in the annual report referred to above.

I am, Sir, yours faithfully,

A. G. Bateman, General Secretary, Medical Defence Union. 4, Trafalgar-square, W.C., July 12th, 1915 .

\section{A CORRECTION}

To the Editor of THE LANCET.

SIR,-With reference to my article on the Progress in the Treatment of Cataract in India recently published by you I wish you to insert this correction. The figures in the Bengal column for 1912 should have been not 2464 but 5679 , and for 1913, instead of 1291, it should have been 5891.

I am, Sir, yours faithfully,

HENRY SMITH, Amritsur, Punjab, June 23rd, 1915. Lieutenant-Colonel, I.M.S.

* * The figures were printed as given in Colonel Smith's manuscript. - ED. L.

\section{THE MEDICAL DIRECTORY, 1916. To the Editor of THE LANCET.}

SIR,-The annual circular for the Medical Directory will be posted to the profession on July 19th. We sincerely hope that all practitioners will make their returns to us as quickly as possible, so that the issue for 1916 may be accurate and full of the latest information. The list of practitioners resident abroad will be reinstated.

We are, Sir, yours faithfully, J. AND A. CHURCHIL.

7, Great Marlborough street, W., July 12th, 1915.

\section{THE POSITION OF SURGEONS TO TRANSPORTS. \\ To the Editor of THE LANCET.}

SIR,-In reply to the letter by "M." in your issue of June 26th, I can quite endorse his remarks on accommodation in many vessels of the Mercantile Marine. Having lately returned to England in a large liner carrying invalids, I found that the surgeon was herded with natives-men, women, and children-for some weeks, and afterwards surrounded by second- and third-class passengers, some of whom were not fit to associate with a respectable working man. When the surgeon spoke to the captain of the steamer about his quarters he was told that, of course, the company could not afford to spare a first-class cabin for him. Medical men intending to serve with the Mercantile Marine should be able now to make just arrangements as to pay and accommodation in the mercantile service, as I hear on good authority that the different com. panies find it hard to get good and trustworthy men. Unfortunately, there are still those who, through their own folly, cannot get work of any description, and these have to accept any position and bear any treatment. As they are on the Register of course they meet the requirements of the Act, but their number is now very small.

July Ist, 1915. 